\title{
Cellular Development of Some Human Organs Before Birth
}

\author{
E. M. WIDDOWSON, D. E. CRABB, and R. D. G. MILNER \\ From Dunn Nutritional Laboratory, Infant Nutrition Research Division, University of Cambridge, and Medical Research \\ Council, and Department of Child Health, University of Manchester
}

\begin{abstract}
Widdowson, E. M., Crabb, D. E., and Milner, R. D. G. (1972). Archives of Disease in Childhood, 47, 652. Cellular development of some human organs before birth. The total amount of DNA and the protein/DNA ratio have been measured in the kidneys, heart, liver, and gastrocnemius muscles of 56 human fetuses and newborn infants of 13-42 weeks' gestational age. The total amount of DNA in each organ approximately doubled every week up to the 25th; thereafter the rate of increase was slower. The protein/DNA ratio in each organ increased rapidly in the last 10 weeks of intrauterine life. Before 30 weeks there was some increase in the protein/DNA ratio in the kidneys, heart, and gastrocnemius muscles, but no significant change in the liver. In 5 small-for-dates infants the protein/DNA ratio was normal, whereas the total DNA tended to be low.
\end{abstract}

The cellular growth of the brain of the human fetus (Winick, 1968; Dobbing and Sands, 1970; Dobbing, 1970), and of the placenta (Winick, Coscia, and Noble, 1967), have been investigated systematically by chemical means, but other organs have been neglected. This paper reports observations on the growth of the human kidneys, heart, liver, and gastrocnemius muscles before birth. Total DNA was used as an index of the number of cells in the internal organs and the protein/DNA ratio as an index of the mean cell size. The quantity of DNA was taken to indicate the number of nuclei in the gastrocnemii, and the protein/DNA ratio the relation between cytoplasm and nucleus.

\section{Materials and Methods}

Organs from 28 fetuses delivered by hysterotomy for the therapeutic termination of pregnancy, and from 28 fresh stillborn and liveborn infants who died within the first week of life were collected. All the fetuses were normal on clinical judgment. Infants with major congenital abnormalities or rhesus incompatability were excluded. Five of the liveborn infants were small for their gestational age, and this was presumably due to nutritional deprivation before birth. Specimens were also collected from 5 adults, 2 men and 3 women, aged 39 to 75 years, for comparison.

The kidneys, heart, liver, and gastrocnemii were collected within one hour of death from the fetuses, weighed to the nearest $\mathrm{mg}$, wrapped in plastic film

Received 21 November 1971.
('Snapwrap'), frozen in liquid nitrogen, and stored $N$ at $-20^{\circ} \mathrm{C}$ until analysed. The same organs were collected from the liveborn infants and adults at necropsy (which was usually performed within 24 hours of death), weighed, and portions were then treated similarly.

The frozen organs were reweighed and were then thawed sufficiently to be homogenized, but the gastrocnemii were ground to a powder in liquid nitrogen. Portions of all the thawed, homogenized tissues were taken for determination of protein and DNA. Protein was precipitated from one sample with $10 \%$ trichloroacetic acid, and nitrogen was determined on the precipitate by the micro-Kjeldahl method (Chibnall, Rees, and Williams, 1943). DNA was extracted by a modification of the method of Zamenhof et al. (1964) using $10 \%$ trichloroacetic acid at the final stage and a temperature of $90{ }^{\circ} \mathrm{C}$ for liver and $70{ }^{\circ} \mathrm{C}$ for other tissues. The final determination was made as described by Burton (1956).

\section{Results}

Fig. 1-4 show the total DNA and the protein/ DNA ratios (mg protein/mg DNA) in the gastrocnemii, kidneys, heart, and liver plotted against $N$ gestational age. A semilogarithmic plot to the N base 2 was used for the total DNA, since this was considered to be the best way of expressing the numbers of dividing cells. The amount of DNA in the muscles and internal organs approximately doubled each week between the 14th and 25th week of gestational age. Thereafter the rate of increase became slower and the range of total 

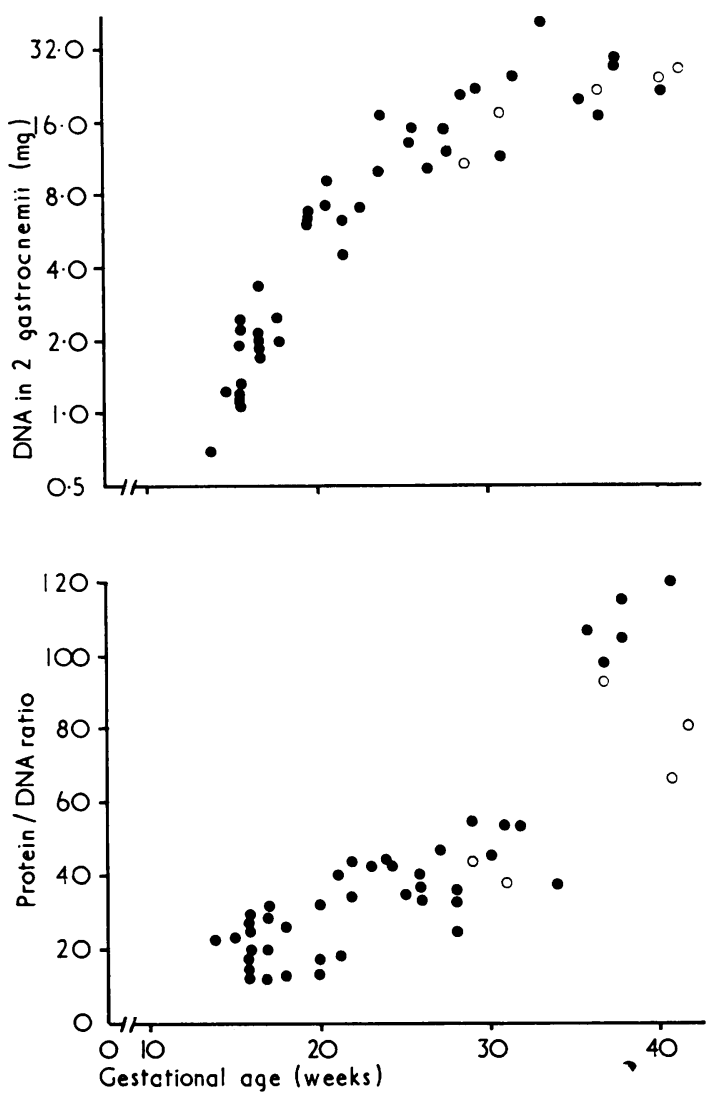

FIg. 1.-Total DNA and protein/DNA ratio in the gastrocnemii, of human fetuses and newborn of 13 to 42 weeks' gestational age. Small-for-dates infants are shown by open circles.

DNA in an organ at any given gestational age became wider. The total amount of DNA in the liver at each stage of gestation was greater than the amount in the other three tissues because of its larger size. The amount of DNA per unit weight however was always highest in the kidneys, and lowest in the skeletal muscles.

There must be a large increase in the amount of DNA in the organs after birth, for at term the total DNA in the fetal kidneys, heart, and liver was less than $20 \%$ of the adult values. In the adult kidneys the mean value was $736 \mathrm{mg}$, range $505-830 \mathrm{mg}$; in the heart $253 \mathrm{mg}$, range 193-355 $\mathrm{mg}$; and in the liver $3862 \mathrm{mg}$, range $2770-4600 \mathrm{mg}$. The total DNA of adult gastrocnemii cannot be given because the whole muscles were not weighed.

The protein/DNA ratio in each organ increased
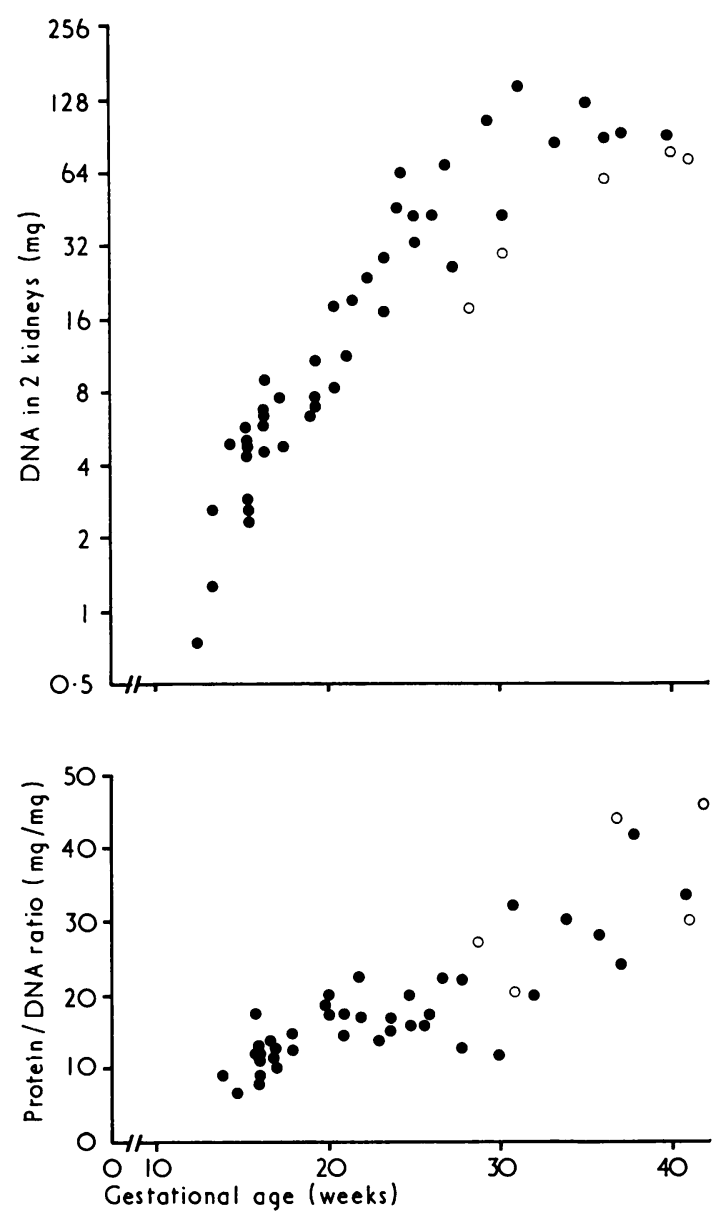

FIG. 2.-Total DNA and protein/DNA ratio in the kidneys of human fetuses and newborn of 13 to 42 weeks' gestational age. Small-for-dates infants are shown by open circles.

rapidly in the last 10 weeks of intrauterine life. Before 30 weeks there was a significant increase in the protein/DNA ratio in kidneys, heart, and gastrocnemii, but no significant change in the protein/ DNA ratio of the liver. The mean ratios (mg protein/mg DNA) in the adult organs were for the kidneys 45 , range $38-64$; for the heart 189 , range 141-234; for the liver 56, range 52-64; for the gastrocnemii 198, range 121-280.

The total DNA of the kidneys, heart, liver, and gastrocnemii of the 5 small-for-dates infants was below or in the lower part of the normal range. The protein/DNA ratio of the same organs in these infants was distributed evenly within the normal range. 

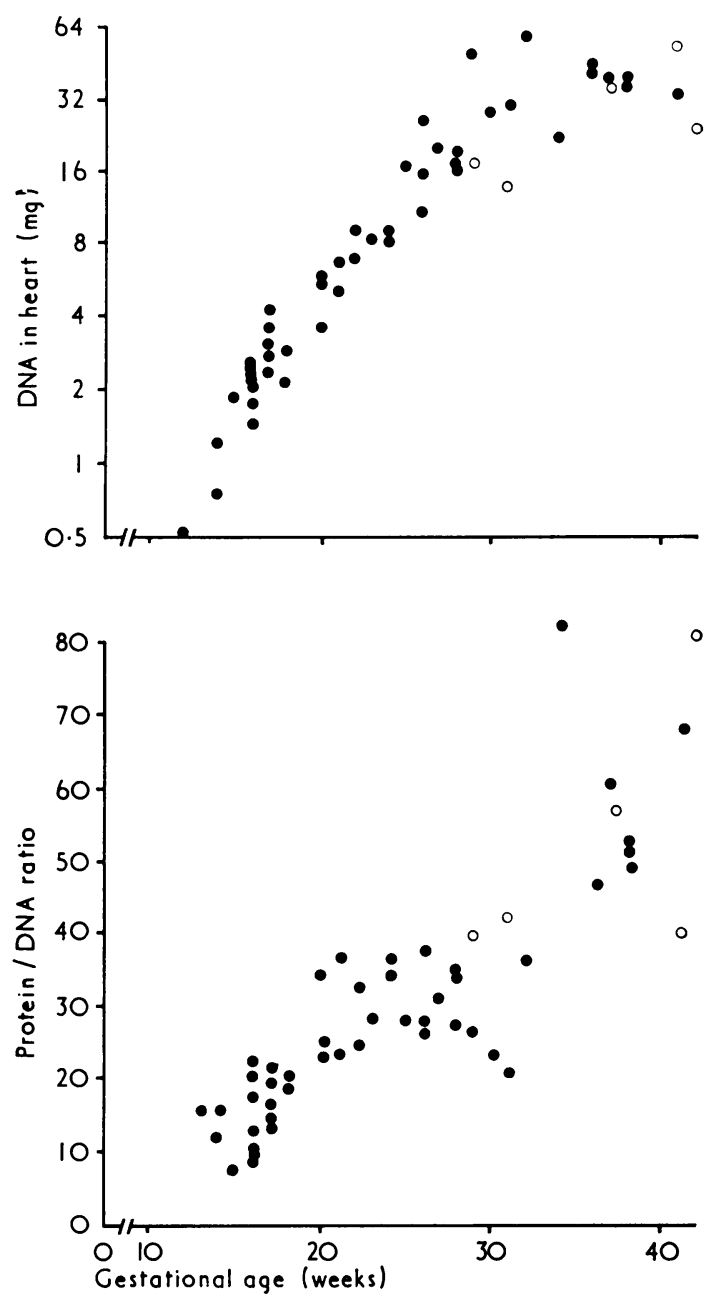

FIG. 3.-Total DNA and protein/DNA ratio in the heart of human fetuses and newborn of 13 to 42 weeks' gestational age. Small-for-dates infants are shown by open circles.

\section{Discussion}

The total DNA and the protein/DNA ratio of different organs have been used in this study as indices of the total cell number and the average cell size of the organ. The validity of this approach has been discussed in detail previously (Problems of Nutrition in the Perinatal Period, 1970). Polyploidy, for instance, occurs in hepatocytes at all ages. There is evidence, however, that the amount of cytoplasm in hepatocytes is proportional to the ploidy of the cell (Epstein, 1967), so that the protein/DNA ratio may still be a valid index of changes in mean cell size. The fetal liver, however,
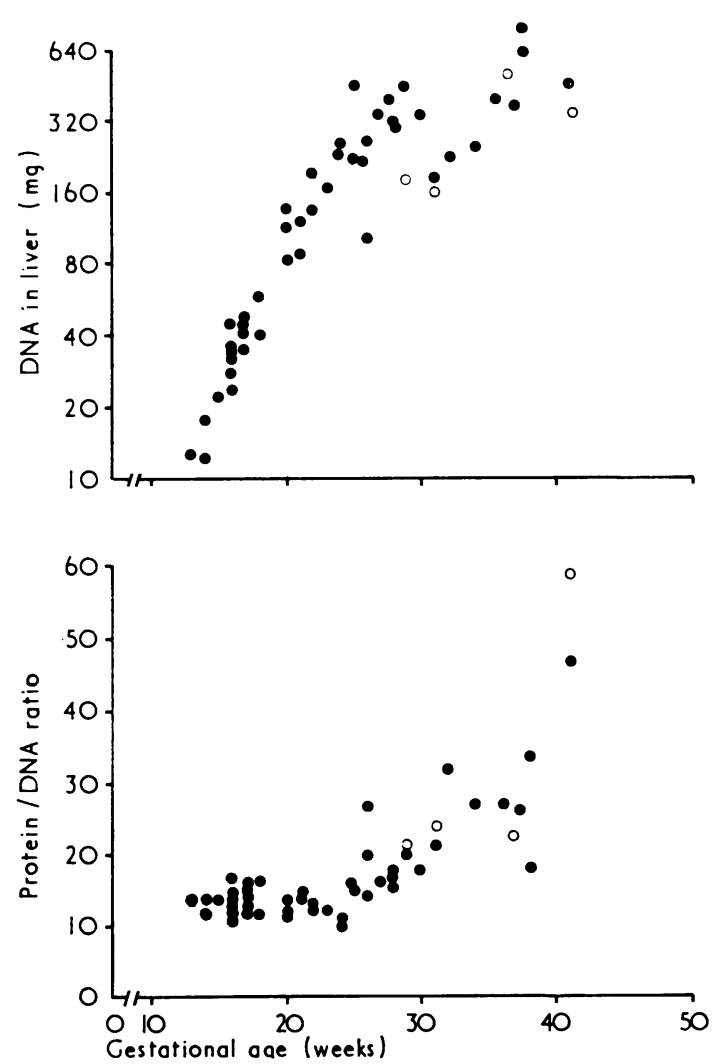

Fig. 4.-Total DNA and protein $\mid D N A$ ratio in the liver of human fetuses and newborn of 13 to 42 weeks' gestational age. Small-for-dates infants are shown by open circles.

is heterogenous, containing both hepatic and haemopoietic tissue. A chemical approach to cellular growth can take no account of the differential growth of the different kinds of cells within an organ.

Total protein rather than intracellular protein was used for the protein/DNA ratio to make the results comparable with those of others (Winick, 1968; Dobbing, and Sands, 1970; Dobbing, 1970; Winick et al., 1967; Winick and Noble, 1966). Earlier studies had shown that about $90 \%$ of the protein in heart and muscle was intracellular at all ages (Dickerson and Widdowson, 1960; Widdowson and Dickerson, 1960), and almost $100 \%$ in liver and kidney.

Despite these reservations the present study has clearly demonstrated two types of cellular growth in the kidney, heart, and liver of the human fetus, which are separated to some extent in time. Between the 14th and 25th weeks of intrauterine life the 


\section{Cellular Development of Some Human Organs Before Birth}

cells in all three organs were dividing rapidly and at a similar rate. In the last 10 weeks there was a rapid growth in cell size. At this time the cells were still dividing, but more slowly, and at term all three organs had still got less than $20 \%$ of the number of cells characteristic of the adult. The cells of the kidney and liver, however, had almost achieved their final size, while those of the heart were approximately half as large as adult cells.

The rate of increase in DNA in the gastrocnemius muscles between the 14th and 25th weeks of gestation was similar to that in the internal organs and, as in them, the rate fell off towards term as the protein/DNA ratio began to increase more rapidly. Even at term, however, the amount of cytoplasm associated with each nucleus was only $60 \%$ of that in the muscles of the adult.

The small-for-dates infants had no deficit in the size of cells in the kidney, heart, and liver, but in each case the number of cells was in the lower part of the normal range. The same was true of the number of nuclei in the gastrocnemii. Similar observations have been made in experimental work on animals (Winick and Noble, 1966; Widdowson, 1971). If the results of animal work can be extrapolated to man, then it is probable that if there is a ceullar deficit resulting from malnutrition in utero this cannot be corrected postnatally.

We thank Professor J. A. Davis for his encouragement and our colleagues in the Department of Gynaecology and Pathology for their co-operation which made this study possible. R. D. G. Milner is grateful to the
Medical Research Council and the Research Grants Committee of the United Manchester Hospitals for financial support.

\section{REFERENCES}

Burton, K. (1956). A study of the conditions and mechanisms of the diphenylamine reaction for the colorimetric estimation of deoxyribonucleic acid. Biochemical fournal, 62, 315.

Chibnall, A. C., Rees, M. W., and Williams, E. F. (1943). The total nitrogen content of egg albumin and other proteins. Biochemical fournal, 37, 354.

Dickerson, J. W. T., and Widdowson, E. M. (1960). Chemical changes in skeletal muscle during development. Biochemical fournal, 74, 247.

Dobbing, J. (1970). Undernutrition and the developing brain: the relevance of animal models to the human problem. American fournal of Diseases of Children, 120, 411.

Dobbing, J., and Sands, J. (1970). Timing of neuroblast multiplication in developing human brain. Nature (London), 226, 639.

Epstein, C. J. (1967). Cell size, nuclear content, and the development of polyploidy in the mammalian liver. Proceedings of the National Academy of Sciences of the United States of America, 57, 327.

Problems of Nutrition in the Perinatal Period (1970). Ross Pediatric Research Conference, 60.

Widdowson, E. M. (1971). Intra-uterine growth retardation in the pig. I. Organ size and cellular development at birth and after growth to maturity. Biology of the Neonate, 19, 329.

Widdowson, E. M., and Dickerson, J. W. T. (1960). The effect of growth and function on the chemical composition of soft tissues. Biochemical fournal, 77, 30.

Winick, M. (1968). Changes in nucleic acid and protein content of the human brain during growth. Pediatric Research, 2, 352.

Winick, M., Coscia, A., and Noble A. (1967). Cellular growth in human placenta. I. Normal placental growth. Pediatrics, 39, 248.

Winick, $M$., and Noble, A. (1966). Cellular response in rats during malnutrition at various ages. Fournal of Nutrition, 89, 300.

Zamenhof, S., Bursztyn, H., Rich, K., and Zamenhof, P. J. (1964). The determination of deoxyribonucleic acid and of cell number in brain. Fournal of Neurochemistry, 11, 505.

Correspondence to Dr. E. M. Widdowson, Dunn Nutritional Laboratory, Infant Nutrition Research Division, Cambridge University, Cambridge. 